\title{
Modeling and Simulation of Two-Staged Separation Process for an Onshore Early Production Facility
}

\author{
Ojo Ademola, J. G. Akpa, K. K. Dagde \\ Department of Chemical Engineering, Rivers State University, Port Harcourt, Nigeria \\ Email: akpa.jackson@ust.edu.ng, dagde.kenneth@ust.edu.ng, ademola.ojo@eunisell.com
}

How to cite this paper: Ademola, O., Akpa, J.G. and Dagde, K.K. (2019) Modeling and Simulation of Two-Staged Separation Process for an Onshore Early Production Facility. Advances in Chemical Engineering and Science, 9, 127-142.

https://doi.org/10.4236/aces.2019.92010

Received: January 7, 2019

Accepted: January 29, 2019

Published: February 1, 2019

Copyright (c) 2019 by author(s) and Scientific Research Publishing Inc. This work is licensed under the Creative Commons Attribution International License (CC BY 4.0).

http://creativecommons.org/licenses/by/4.0/

\begin{abstract}
Early Production Facilities are makeshift process deployment that ensures that marginal oilfield operators make revenues from their new discoveries with little cash outlay and limited investment risks. Authors have in past simulated a gas process facility using Hysys without particularly developing mathematical models for the key equipment. There also has been modeling of phase separation dynamics and process simulation but still without models for equipment. We basically developed models for the critical process equipment for early production, sized the equipment with data from a marginal field in the Niger delta region of Nigeria and then ran a dynamic simulation with the sized equipment. The important elements of the deployment are two-phase process vessel, 3-phase process vessel; knock-out drum, produced water treatment unit. Mathematical models were developed and adapted with Mathlab for the equipment sizing whilst ASPEN PLUS was used for simulating the process. Process data retrieved from a marginal field in Nigeria was used as input to quantify the equipment models. Sized equipment was deployed in Hysys V8.8 for a steady and dynamic state. The system simulation was comprised of a two-phase process vessel followed by a 3-phase process vessel [1]. The unwanted gas was sent to knock out drum for removal of entrained liquid droplets before flaring (this was because the volume of gas processed is deemed uneconomical) and produced water to treatment unit for removing droplets of oil before disposal. Gas, oil and water were fed into the first stage separator (2-phase) at $132918.34 \mathrm{Ibmole} / \mathrm{hr}, 7622.95 \mathrm{Ibmole} / \mathrm{hr}$ and 1082.74 Ibmole/hr respectively. The operating pressures of the first and second vessels were at 850 psi and 150 psi respectively. The 2-phase vessel flashed off $96.7 \%$ of the gas and increased the liquid recovery by $3.3 \%$. At the end of the second stage separation, oil yield increased by $270 \mathrm{Ibmole} / \mathrm{hr}$, the gas increased by $110.15 \mathrm{Ibmole} / \mathrm{hr}$ whilst water reduced by $379 \mathrm{Ibmole} / \mathrm{hr}$. This result con-
\end{abstract}


firmed that the vessels were sized to optimize recovery of hydrocarbons entrained in the various phases into the most required oil phase.

\section{Keywords}

Modeling and Simulation, 2-Phase Process Vessel, 3-Phase Process

Vessel, Effective Length, Seam-Seam Length, Slenderness Ratio

\section{Introduction}

Oil exploration is a capital intensive investment. It comes with a lot of cash outlay requirements before generation of economic returns or bottomline. In the Nigerian context, Marginal fields are deemed economically viable and licenses are always allocated to locals. Sometimes they are referred to as marginal when they constitute a divested asset from a major international oil company such as Shell, Chevron, Agip, Total etc. whilst other times they are unexplored oil blocks with average reservoir capacity from seismic studies [2]. The challenge of developing a marginal field often lies in accessibility of funds ranging from those required for drilling, completions, and constructing of surface production facilities to operational services. Experience has shown that the delays between approvals of licenses to realization of full field optimization are a direct consequence of lack of funds. The cost of field development is quite high. Many marginal fields after drilling and completions are left for as long as ten years trying to source for funds to construct the crude process facility. The essence of this study is to design and test by simulating a makeshift crude process facility that will greatly reduce the cash outlay requirement and bring first oil realization to fruition quickly. With the solution proffered, marginal field operators can quickly convert their existing reservoir asset to cash whilst planning expansion or full field development. It will simply ensure the operators have cash generation from their assets in order to fund the field development. This ideally is every investor's dream.

Crude oil production operation is key to the petroleum and gas industry as its efficiency determines the quality of the crude and ultimately the economics of it all. Surface production operation is basically a set of unit operations required to treat crude oil to meet certain export requirements and also ensure that the set of activities required to achieve these is environmental friendly and poses to health and safety threat to human and animal life.

The concept of this study is to flow multiphase well fluid from the well through four basic process vessels with different handling capacities. The vessels were sized based on envisaged fluid flow characteristics and rates. The bulk liquid hydrocarbon was the content of interest and was passed through a three-stage separation process. The first stage was comprised of a two-phase separator i.e. separates fluid into gas and liquid phases. Phase equilibrium dynamics guides the bulk of the separation by flashing of the vapor out of the liquid 
phase. Separation degree of the vapor phase was expected to be at $96 \%-98 \%$ depending on nature of the multiphase whilst the remaining vapor \% was retained in the liquid phase [3]. This stage vessel was operated at a much higher pressure and it will present unstable crude to the next process stage.

The second process stage was comprised of a three-phase separator that separated the fluid into three phases i.e. oil, gas and water. The separator was operated at a much lower pressure and at reduced fluid velocity ensuring that the unstable light hydrocarbons in the liquid phase becomes stable and flashes into the gas phase [4]. About 3\% entrained gas in the liquid phase was dislodged into the vapor phase. This ensures that the vapor pressure of the liquid was considerably reduced in order to reduce volatility and explosive tendencies of the crude oil [5]. Causing a change in thermodynamic property of the fluid mixture here supports the kind of separation expected. Retention time of the fluid in the vessel played a vital role in aiding the separation of the oil from the water. Practically, this was achieved by allowing a reasonably high vapor liquid interface height in the vessel and operating the vessel at a relatively low pressure. All these conditions ensured that the fluid phases were adequately in contact with each other resulting to phase equilibriums and other conditions necessary to cause separation by gravity [4].

Some of the export requirements for crude oil are the basic sediment and water (BS \& W) content which must be less than $0.5 \%$, the vapor pressure which must be considerably about the Reid's vapor pressure (Absolute pressure of the vapor of the crude oil at $37.8^{\circ} \mathrm{C}$ following the ASTM-D323 test method). RVP is also a function of measure of the stability of the crude oil [4]. It ensures that the volatility is reasonably within a limit that the crude can be safely pumped and transported through pipelines at prevailing environmental conditions without constituting explosive mixtures. Environmental impact control of the crude process operation includes the treatment of the produced water to remove the oil droplets entrained with it. The presence of oil in water at disposal would cause harm to aquatic and plant lives. It reduces the amount of oxygen present in the water bodies for aquatic lives to live thereby impacting on their lives. Presence of crude oil in water disposed of on land interfered with the efficacy of the soil nutrient thereby reducing or completely eliminating soil yield. The droplets of liquid entrained in the continuous gas phase to the flare was removed to ensure gas burns completely and efficiently without deposition of carbon on land that may cause harmful impact of soil fertility and crop survival [6].

Some work has been done in this regards in the past.

\section{Models Development}

The following assumptions were made in the design and simulation of the process:

- The multiphase mixture is without foam and emulsion, conditions that would drastically cause an extension of the retention times required.

- The pour and hydrate points of the liquid hydrocarbon are reasonably below 
the operating temperatures of all vessels. These ensure no wax or hydrate formation and eliminate the need for chemical injection.

- The smallest separable liquid droplet from all phases is in order of $500 \mu \mathrm{m}$.

- The liquid carry over in the gas line is negligible and insignificant.

\subsection{Gravity Settling Model}

Phase separation is largely done under influence of gravity as supported by Stoke's law. However, the law has different regimes and does not guide all separation cases.

The separation envisaged here is of liquid droplets settling through the prevailing continuous phase of either gas or oil. Inside the two phase vessel, it is envisaged that the liquid droplets (oil and water) will settle through the continuous gas phase to ensure two phase separation. In fluid mechanics, that liquid droplet will settle with a terminal velocity under influences of the drag and buoyant forces.

$$
F_{D}=C_{D} A \rho_{g}\left[\frac{V_{t}^{2}}{2 g}\right]
$$

where $F_{D}$ is the Drag Force, Ib, $C_{D}$ is the drag coefficient, $A$ is the area of the liquid droplet, $\mathrm{ft}^{2} \rho_{g}$ is the density of the gas medium, $\mathrm{Ib} / \mathrm{ft}^{3}, V_{t}$ is the terminal velocity in $\mathrm{ft} / \mathrm{s}, g$ is the gravitational acceleration at $32.2 \mathrm{ft} / \mathrm{s}^{2}$.

When the flow is laminar, then the Stoke's law is effective and the quantity $C_{D}$ is given thus:

$$
\begin{gathered}
C_{D}=\frac{24}{R e} \\
R e=\frac{\rho_{g} D V_{t}}{\mu_{g}}
\end{gathered}
$$

Substituting Equation (2) and Equation (3) into Equation (1) and simplifying yields:

$$
F_{D}=\frac{24}{\frac{\rho_{g} D V}{\mu_{g}}}\left[\frac{\pi D^{2}}{4}\right] \rho_{g} \frac{V_{t}^{2}}{2 g}
$$

Essentially, the droplet continue to accelerate until a terminal velocity is reached at which point the drag force equates the buoyancy force from the principle of Achimedes. It is also assumed that the Stoke's law can guide the droplet movement when the flow is laminar in nature and therefore

$$
F_{D}=3 \pi \mu^{\prime} D V_{t}
$$

Again the Bouyancy force acting on the body from the principle of Achimedes is given thus:

$$
F_{B}=\left(\rho_{l}-\rho_{g}\right) \frac{\pi D^{3}}{6}
$$

Equating Equation (5) and Equation (6) and simplifying for $V_{t}$, we have the 
following equation:

$$
V_{t}=\left(\frac{\rho_{l}-\rho_{g}}{18 \mu}\right) D^{2}
$$

where: $D=$ Liquid droplet diameter, $\mathrm{ft}, \mu^{\prime}=\mu\left(2.088 \times 10^{-5}\right)$, Viscosity in cp, $D=$ $d_{m}\left(3.281 \times 10^{-6}\right), \quad \rho_{l}=62.4 \times S . G, \quad \rho_{g}=62.4 \times$ S.G.

Therefore Equation (7) simplifies as:

$$
V_{t}=\frac{1.78 \times 10^{-6}(\Delta S . G) d m^{2}}{\mu}
$$

Practically in the industrial situations, the flows are not always laminar and it becomes difficult for the Stoke's law to guide. Hence the following expression for $C_{D}$ suffices:

$$
C_{D}=\frac{24}{R e}+\frac{3}{R e^{\frac{1}{2}}}+0.34
$$

Substituting Equation (9) into Equation (2) and then equating $F_{B}$ and $F_{D}$ then simplifying will yield the desired applicable $V_{t}$ in practical scenarios.

$$
V_{t}=\left[\left(\frac{\rho_{l}-\rho_{g}}{\rho_{g}}\right) \frac{d_{m}}{C_{D}}\right]^{\frac{1}{2}}
$$

\subsection{Model Development for a 2-Phase Process Vessel}

\subsubsection{Gas Capacity Constraint}

Basically two constraints govern process vessel design:

- Gas Capacity constraint which ensures that the liquid droplet is permitted to settle by gravity according to Equation (10) through the continuous gas phase.

- Liquid Capacity Constraint which must be sufficient enough to allow liquid-liquid equilibrium for separation to occur.

The designs are for assumed situations when the vessels are operated half filled with liquid.

Assuming $A_{g}$ is the area of the vessel occupied by gas in $\mathrm{ft}^{2}, V_{g}$ is the velocity of the gas in $\mathrm{ft} / \mathrm{s}$ and $Q$ is the flow rate in $\mathrm{ft}^{3} / \mathrm{s}$ :

$$
\begin{gathered}
V_{g}=\frac{Q}{A_{g}} \\
A_{g}=\frac{1}{2}\left[\frac{\pi}{4} D^{2}\right]=\frac{1}{2}\left(\frac{\pi}{4} \frac{d^{2}}{144}\right)=\frac{d^{2}}{367}
\end{gathered}
$$

$Q_{g}$ is in MMSCfd

$$
\begin{aligned}
Q & =Q_{g} \times 10^{6} \frac{\mathrm{SCF}}{\mathrm{MMSCF}} \times \frac{\text { day }}{24 \mathrm{hr}} \times \frac{\mathrm{hr}}{3600 \mathrm{~s}} \times \frac{14.7}{P} \times \frac{T Z}{520} \\
& =0.327 \frac{T Z}{P} Q_{g}
\end{aligned}
$$

Substituting Equation (12) and Equation (13) into Equation (11) yields 


$$
\begin{gathered}
V_{g}=\frac{\left(0.327 \frac{T Z}{P} Q_{g}\right)(367)}{d^{2}} \\
V_{g}=120 \frac{T Z Q_{g}}{P d^{2}}
\end{gathered}
$$

If we set the residence time of the gas to be the time required for a liquid droplet in its continuous phase to settle down to the gas liquid interface, then:

$$
t_{g}=\frac{L_{e f f}}{V_{g}}
$$

Residence time of gas $t_{d}=\frac{D}{2 V_{t}}$ converting $D$ in $\mathrm{ft}$ to $d$ in inches $\therefore t_{d}=\frac{d}{24 V_{t}}$ : Time required for a liquid droplet to settle down to the gas-oil interface $t_{g}=$ residence time of gas; $t_{d}=$ time necessary for a liquid droplet to settle from constinuos gas phase to gas liquid interface.

$$
t_{g}=\frac{L_{e f f}}{120\left[\frac{T Z Q_{g}}{P d^{2}}\right]}: V_{t}=0.0119\left[\left(\frac{\rho_{l}-\rho_{g}}{\rho_{g}}\right) \frac{d m}{C_{D}}\right]^{1 / 2}
$$

If $t_{g}=t_{d}$ with simplification

$$
d l_{\text {eff }}=420 \frac{T Z Q_{g}}{P}\left[\left(\frac{\rho_{g}}{\rho_{l}-\rho_{g}}\right) \frac{C_{D}}{d_{m}}\right]^{1 / 2}
$$

\subsubsection{Liquid Capacity Constraint}

For a liquid droplet settling through a continuous fluid phase with a retention time $t$ in second, the following expression finds relevance:

$$
t=\frac{V}{Q}
$$

where $V o l=\frac{1}{2} \frac{\pi D^{2}}{4} l_{\text {eff }}=2.73 \times 10^{-3} d^{2} L_{\text {eff }}$

$$
\begin{gathered}
Q=Q_{1} \times 5.61 \frac{\mathrm{ft}^{3}}{\text { barrel }} \times \frac{\text { day }}{24 \mathrm{hr}} \times \frac{\mathrm{hr}}{3600 \mathrm{~s}} \neq^{1} 6.49 \times 10^{-5} Q_{1} \\
t=42.0 \frac{d^{2} L_{e f f}}{Q_{1}} \\
d^{2} L_{e f f}=\frac{t_{r} Q_{l}}{0.7}
\end{gathered}
$$

$t_{r}=$ Desired retention time for the liquid, min; $Q_{I}=$ Liquid flow rate in bpd.

\subsubsection{Seam to Seam Length}

$D$ and $L_{e f f}$ are the vessel diameter and effective length respectively. However, in order to ensure incorporation of useful and important control mechanisms, the vessel length has to be slightly extended to accommodate for the instruments [3] [4]. 


$$
L_{s s}=L_{e f f}+\frac{d}{12}
$$

And

$$
L_{s s}=\frac{4}{3} L_{e f f}
$$

Equation (18) suffices for cases of Gas Capacity governing the design whilst Equation (19) suffices in event of Liquid Capacity governed designs.

\subsection{Three Phase Process Vessel Design}

The bulk liquid separation and flashing of the retained 3\% gas in the stream takes place in the gravity section of the 3-phase process vessel. A gas and liquid capacity constraint also governs the design of the vessel here.

\subsubsection{Gas Capacity Constraint}

Liquid droplets separates out under the medium influence of forces in the continuous gas phase and the phenomenon is same for both the two and three phase process vessels. Hence Equation (16) remains valid

$$
d L_{\text {eff }}=420 \frac{T Z Q_{g}}{P}\left[\left(\frac{\rho_{g}}{\rho_{l}-\rho_{g}}\right) \frac{C_{D}}{d_{m}}\right]^{1 / 2}
$$

\subsubsection{Liquid Capacity Constraint}

Also referred to as retention time constraint starts off with an expression of retention time for the liquids to separate out of the bulk three phase fluid interaction.

$$
t=\frac{V o l}{Q}
$$

$$
\begin{aligned}
& \text { And } V o l=\frac{1}{2}\left(\frac{\pi D^{2}}{4} L_{e f f}\right)=\frac{\pi d^{2}}{(2)(4)(144)} 2.73 \times 10^{-3} d^{2} L_{e f f} \\
& (V o l)_{o}=2.73 \times 10^{-3} d^{2} L_{e f f}\left(\frac{A_{o}}{A_{l}}\right) \\
& (V o l)_{w}=2.73 \times 10^{-3} d^{2} L_{e f f}\left(\frac{A_{w}}{A_{l}}\right)
\end{aligned}
$$

And $Q_{D}$ and $Q_{w}$ are both in bpd

$$
\begin{gathered}
Q=Q_{o} \times 5.61 \frac{\mathrm{ft}^{3}}{\text { banel }} \times \frac{\text { day }}{24 \mathrm{hr}} \times \frac{\mathrm{hr}}{3600 \mathrm{~s}}=6.49 \times 10^{-5} Q_{o} \\
Q=6.49 \times 10^{-5} Q_{w}
\end{gathered}
$$

$A_{o}, A_{w}$ and $A_{l}$ are cross sectional areas of oil, water and liquid respectively.

$$
42\left(\frac{A_{o}}{A_{I}}\right)=\frac{t_{o} Q_{o}}{d^{2} L_{e f f}} ; \quad 42\left(\frac{A_{w}}{A_{1}}\right)=\frac{t_{w} Q_{w}}{d^{2} L_{e f f}}
$$

$\left(t_{r}\right)_{o}$ and $\left(t_{r}\right)_{W}$ are in minutes 


$$
\begin{aligned}
0.7\left(\frac{A_{o}}{A_{I}}\right) & =\frac{\left(t_{r}\right)_{o} Q_{o}}{d^{2} L_{\text {eff }}} ; 0.7\left(\frac{A_{w}}{A_{1}}\right)=\frac{\left(t_{r}\right)_{w} Q_{w}}{d^{2} L_{\text {eff }}} \\
d^{2} L_{\text {eff }} & =1.42\left[\left(t_{r}\right)_{o} Q_{o}+\left(t_{r}\right)_{w} Q_{w}\right]
\end{aligned}
$$

where $Q_{W}=$ water flow rate, bpd, $\left(t_{r}\right)_{W}=$ water retention time, minutes, $Q_{o}=$ Oil flow rate, bpd, $\left(t_{r}\right)_{o}=$ Oil retention time, minutes

To ensure that 500-micron of water droplet are permitted to settle out of oil pad, the oil pad thickness has to be constrained thus;

$$
t_{w}=\frac{h_{o} / 12}{V_{t}}
$$

where $V_{t}=\frac{1.78 \times 10^{-6}(\Delta S . G) d m^{2}}{\mu}$

$$
\begin{gathered}
t_{w}=46800 \frac{\mu h_{o}}{(\Delta S . G) d m^{2}}: t_{w}=t_{o} \\
t_{o}=60\left(t_{r}\right)_{o} \\
46800 \frac{\mu h_{o}}{(\Delta S \cdot G) d m^{2}} 60\left(t_{r}\right)_{o} \\
h_{o}=\frac{0.00128\left(t_{r}\right)_{o}(\Delta S \cdot G) d m^{2}}{\mu}
\end{gathered}
$$

Above equation must be satisfied for water droplet to settle out of oil. $h_{o}$ is the max thickness for this to be valid.

For $d_{m}=500$ micron

$$
\left(h_{o}\right)_{\text {mass }}=320 \frac{\left(t_{r}\right)_{o}(\Delta S . G)}{\mu}
$$

$t_{r}$ is in minutes, $t_{w} t_{o}$ are in seconds, $V$ is in $\mathrm{ft} / \mathrm{s}, h_{o}$ is in inches, $d_{m}$ is in micron, $\mu$ is in cp.

Similarly, for given oil retention time and water retention time, $\left(h_{o}\right)_{\max }$ constraint establishes max constraint establishes maximum diameter thus:

$$
\begin{gathered}
A=\frac{Q_{t}}{L_{\text {eff }}} \\
Q=6.49 \times 10^{-5} Q_{o} \\
Q=6.49 \times 10^{-5} Q_{w} \\
t_{o}=60\left(t_{r}\right)_{o} \\
t=60\left(t_{r}\right)_{w} \\
A_{o}=3.89 \times 10^{-3} \frac{Q_{o}\left(t_{r}\right)_{o}}{L_{e f f}} \\
A_{w}=3.89 \times 10^{-3} \frac{Q_{w}\left(t_{r}\right)_{w}}{L_{e f f}}
\end{gathered}
$$




$$
\begin{gathered}
A=2\left(A_{o}+A_{w}\right) \\
\frac{A_{w}}{A}=0.5\left[\frac{Q_{w}\left(t_{r}\right)_{w}}{\left(t_{r}\right)_{o} Q_{o}+\left(t_{r}\right)_{w} Q_{w}}\right]
\end{gathered}
$$

The fraction of vessel cross-sectional area occupied by water

$$
\begin{aligned}
d_{\max } & =\frac{\left(h_{o}\right)_{\max }}{\beta} \\
\beta & =h_{o} \frac{1}{d}
\end{aligned}
$$

\subsubsection{Seam-Seam Length and Slenderness Ratio}

The essence and method of determination of seam to seam lengths and slenderness ratio is same for process vessels. Slenderness ratio is practically limited to 3 - 4 for prevention of re-entrainment of liquid at the gas/liquid interface.

Slenderness ratio higher than 4 can be slightly acceptable for three-phase process vessel, when the gas content is small.

\section{Results and Discussions}

The models developed for each of the vessels were solved using Mathlab whilst the simulation was performed with Aspen Hysys v8.8. Process vessels are specified by their diameter in inches and length in feet. Standardly, the vessels diameter is expanded in 6 "increments whilst the lengths are expanded in 2.5" increments [7] [8]. Data (compositional Feed characteristics and equipment parameters) were taken from a marginal field in the Niger Delta Oil producing area of Nigeria to size the equipment and run the simulation. These are shown in $\mathrm{Ta}$ ble 1 and Table 2 .

The feed input to Hysys requires compositional analysis of all streams. These data were deployed for the simulation of the process.

This second set of bulk fluid data were used as equipment sizing parameters for the two vessels.

\subsection{Two Phase Process Vessel Sizing}

Table 3 shows standard vessel sizes available in the industry and from where reference would be drawn in our sizing

1) The Drag Coefficient $C_{D}$ was calculated at few iterative steps using Mathlab

$$
C_{D}=0.829
$$

2) Gas Capacity Constraint

$$
d L_{\text {eff }}=3.5478
$$

The Gas Capacity Constraint apparently will not govern due its relatively low value.

3) Liquid Capacity Constraint

$$
d^{2} L_{\text {eff }}=21429 .
$$

This quantity will govern due to its realistic value. 
Table 1. Compositional feed characteristics.

\begin{tabular}{|c|c|c|c|c|}
\hline SN & Components & Gas Stream \% & Oil Stream \% & Water Stream \% \\
\hline 1 & $\mathrm{~N}_{2}$ & 0.04 & 0.00 & 0.05 \\
\hline 2 & $\mathrm{CO}_{2}$ & 1.13 & 0.00 & 0.10 \\
\hline 3 & $\mathrm{H}_{2} \mathrm{O}$ & 0.01 & 0.00 & 97.03 \\
\hline 4 & $\mathrm{C}_{1}$ & 85.21 & 5.00 & 0.05 \\
\hline 5 & $\mathrm{C}_{2}$ & 6.34 & 0.01 & 0.17 \\
\hline 6 & $\mathrm{C}_{3}$ & 4.1 & 0.01 & 1.3 \\
\hline 7 & i- $\mathrm{C}_{4}$ & 0.87 & 0.01 & 1.3 \\
\hline 8 & $\mathrm{n}-\mathrm{C}_{4}$ & 1.36 & 0.02 & 0.00 \\
\hline 9 & $\mathrm{i}-\mathrm{C}_{5}$ & 0.43 & 0.02 & 0.00 \\
\hline 10 & $\mathrm{n}-\mathrm{C}_{5}$ & 0.36 & 0.03 & 0.00 \\
\hline 11 & $\mathrm{C}_{6}$ & 0.11 & 0.10 & 0.00 \\
\hline 12 & $\mathrm{C}_{7}$ & 0.03 & 90.12 & 0.00 \\
\hline 13 & $\mathrm{C}_{8}$ & 0.01 & 0.08 & 0.00 \\
\hline 14 & $\mathrm{C}_{9}$ & 0.00 & 0.60 & 0.00 \\
\hline 15 & $\mathrm{C}_{10}$ & 0.00 & 2.0 & 0.00 \\
\hline 16 & $\mathrm{C}_{11}$ & 0.00 & 2.0 & 0.00 \\
\hline \multicolumn{5}{|c|}{ Flow Parameters } \\
\hline \multicolumn{2}{|c|}{ Pressure (psi) } & 900 & 900 & 900 \\
\hline \multicolumn{2}{|c|}{ Temperature $\left({ }^{\circ} \mathrm{F}\right)$} & 118.4 & 118.4 & 118.4 \\
\hline \multicolumn{2}{|c|}{ Viscosity (cp) } & 0.0119 & & 1.01 \\
\hline \multicolumn{2}{|c|}{ Specific Gravity } & 0.65 & 0.825 & 1.07 \\
\hline \multicolumn{2}{|c|}{ Flow rates } & 3 & 7500 & 1500 \\
\hline
\end{tabular}

Table 2. Equipment input design parameters.

\begin{tabular}{ccccc}
\hline Parameter & 2-phase separator & 3-phase separator & Knock out drum & $\begin{array}{c}\text { Produced water } \\
\text { treatment unit }\end{array}$ \\
\hline Temp, ${ }^{\circ} \mathrm{F}$ & 118.4 & 118.4 & 118.4 & 118.4 \\
Pressure, psi & 900 & 150 & 50 & 50 \\
$S G_{w}$ & 1.07 & 1.07 & 1.07 & 1.07 \\
$S G_{o}$ & 0.825 & 0.825 & 0.825 & 0.825 \\
$S G_{g}$ & 0.65 & 0.65 & 0.65 & 0.65 \\
$\rho_{o}, \mathrm{Ib} / \mathrm{ft}^{3}$ & 51.48 & 51.48 & 51.48 & 51.48 \\
$\rho_{w} \mathrm{Ib} / \mathrm{ft}^{3}$ & 66.76 & 66.76 & 66.76 & 66.76 \\
$\rho_{g}, \mathrm{Ib} / \mathrm{ft}^{3}$ & 4.02 & 4.02 & 4.02 & 4.02 \\
$\mu_{o}, \mathrm{cp}$ & & & & \\
$\mu_{w}, \mathrm{cp}$ & 1.01 & 1.01 & 1.01 & 1.01 \\
$\mu_{g}, \mathrm{cp}$ & 0.0119 & 0.0119 & 0.0119 & 0.0119 \\
$Q_{o}, \mathrm{bpd}$ & 7500 & 7500 & 7.5 & \\
$Q_{w}, \mathrm{bpd}$ & 1500 & 1500 & & \\
$Q_{g}, \mathrm{mmscfd}$ & 3 & 3 & 3 & \\
\hline
\end{tabular}


Table 3. Standard horizontal process vessel sizes [4] [9].

\begin{tabular}{|c|c|c|c|c|c|c|}
\hline Size $[D($ inch $)$ by $L(\mathrm{ft})]$ & & Maximum & Allowable & Working & Pressures (PSI) & $@ 100^{\circ} \mathrm{F}$ \\
\hline $16^{\prime \prime} \times 5^{\prime}$ & & 230 & 600 & 1000 & 1440 & 2000 \\
\hline $16^{\prime \prime} \times 7^{1 / 2}$ & & 230 & 600 & 1000 & 1440 & 2000 \\
\hline $16^{\prime \prime} \times 10^{\prime}$ & & 230 & 600 & 1000 & 1440 & 2000 \\
\hline $20^{\prime \prime} \times 5^{\prime}$ & & 230 & 600 & 1000 & 1440 & 2000 \\
\hline $20^{\prime \prime} \times 7^{1 / 2}$ & & 230 & 600 & 1000 & 1440 & 2000 \\
\hline $20^{\prime \prime} \times 10^{\prime}$ & & 230 & 600 & 1000 & 1440 & 2000 \\
\hline $24^{\prime \prime} \times 5^{\prime}$ & 125 & 230 & 600 & 1000 & 1440 & 2000 \\
\hline $24^{\prime \prime} \times 7^{1 / 2}$ & 125 & 230 & 600 & 1000 & 1440 & 2000 \\
\hline $24 " \times 10^{\prime \prime}$ & 125 & 230 & 600 & 1000 & 1440 & 2000 \\
\hline $30^{\prime \prime} \times 5^{\prime}$ & 125 & 230 & 600 & 1000 & 1440 & 2000 \\
\hline $30^{\prime \prime} \times 7^{1 / 2}$ & 125 & 230 & 600 & 1000 & 1440 & 2000 \\
\hline $30^{\prime \prime} \times 10^{\prime}$ & 125 & 230 & 600 & 1000 & 1440 & 2000 \\
\hline $36^{\prime \prime} \times 5^{\prime}$ & 125 & 230 & 600 & 1000 & 1440 & 2000 \\
\hline $36^{\prime \prime} \times 7^{1 / 2}$ & 125 & 230 & 600 & 1000 & 1440 & 2000 \\
\hline $36^{\prime \prime} \times 10^{\prime}$ & 125 & 230 & 600 & 1000 & 1440 & 2000 \\
\hline $36^{\prime \prime} \times 15^{\prime}$ & 125 & 230 & 600 & 1000 & 1440 & 2000 \\
\hline $42^{\prime \prime} \times 7^{1 / 2}$ & 125 & 230 & 600 & 1000 & 1440 & 2000 \\
\hline $42^{\prime \prime} \times 10^{\prime}$ & 125 & 230 & 600 & 1000 & 1440 & 2000 \\
\hline $42^{\prime \prime} \times 15^{\prime}$ & 125 & 230 & 600 & 1000 & 1440 & 2000 \\
\hline $48^{\prime \prime} \times 7^{1 / 2}$ & 125 & 230 & 600 & 1000 & 1440 & 2000 \\
\hline $48^{\prime \prime} \times 10^{\prime}$ & 125 & 230 & 600 & 1000 & 1440 & 2000 \\
\hline $48^{\prime \prime} \times 15^{\prime}$ & 125 & 230 & 600 & 1000 & 1440 & 2000 \\
\hline $54^{\prime \prime} \times 7^{1 / 2}$ & 125 & 230 & 600 & 1000 & 1440 & 2000 \\
\hline $54^{\prime \prime} \times 10^{\prime}$ & 125 & 230 & 600 & 1000 & 1440 & 2000 \\
\hline $54^{\prime \prime} \times 15^{\prime}$ & 125 & 230 & 600 & 1000 & 1440 & 2000 \\
\hline $54^{\prime \prime} \times 20^{\prime}$ & 125 & 230 & 600 & 1000 & 1440 & 2000 \\
\hline $60^{\prime \prime} \times 10^{\prime}$ & 125 & 230 & 600 & 1000 & 1440 & 2000 \\
\hline $60^{\prime \prime} \times 15^{\prime}$ & 125 & 230 & 600 & 1000 & 1440 & 2000 \\
\hline $60^{\prime \prime} \times 20^{\prime}$ & 125 & 230 & 600 & 1000 & 1440 & 2000 \\
\hline $66^{\prime \prime} \times 15^{\prime}$ & 125 & 230 & 600 & 1000 & 1440 & 2000 \\
\hline $66^{\prime \prime} \times 20^{\prime}$ & 125 & 230 & 600 & 1000 & 1440 & 2000 \\
\hline $66^{\prime \prime} \times 22^{1 / 2}$ & 125 & 230 & 600 & 1000 & 1440 & 2000 \\
\hline $72^{\prime \prime} \times 15^{\prime}$ & 125 & 230 & 600 & 1000 & 1440 & 2000 \\
\hline $72^{\prime \prime} \times 20^{\prime}$ & 125 & 230 & 600 & 1000 & 1440 & 2000 \\
\hline $72^{\prime \prime} \times 22^{1 / 2}$ & 125 & 230 & 600 & 1000 & 1440 & 2000 \\
\hline
\end{tabular}

4) Estimation of the Seam to Seam Length based on the governing liquid capacity constraint must provide a value between 3 and 4 to eliminate re-entrainment ten- 
dencies.

Upon selecting reasonable diameter vs. effective lengths combinations, seam to seam lengths were also calculated with corresponding slenderness ratios. The following specification best describes the equipment size for this application:

From the retention time constraint quantity, the various diameters and lengths combinations are shown in Table 4.

Given the slenderness ratio value which is must be between 3 and 4 to eliminate re-entrainment tendencies, the two-phase vessel selected is shown in Table 5.

\subsection{Three Phase Process Vessel Sizing}

1) Retention time is taken to be $1 \mathrm{~min}$.

2) $\left(h_{o}\right)_{\max }$ is the maximum oil pad thickness that will permit the sized droplets of water to settle to bottom of the vessel and permit the sized oil droplet to rise to oil-water interface and it is calculated to be 13.44 inch.

3) $\frac{A_{w}}{A}$ represents the fraction of the vessel filled with water and calculated as 0.009 .

4) $h_{o} / d$ is the ratio of the oil pad thickness (based oil production rate envisaged and fluid properties) to the diameter of the vessel and it is calculated as 0.48 .

5) $d_{\max }=277$.

6) The gas capacity constraint value from

$$
d L_{\text {eff }}=8.6390 \text {. }
$$

Apparently too small and will not govern design.

7) The liquid capacity constraint as determined from $d^{2} L_{\text {eff }}=108630$.

8) Since the oil and water retention time constraint governs, the Seam to Seam lengths for $d$ and $L_{\text {eff }}$ combinations are tabulated in Table 6.

Referencing the standard industrial sizes and considering the slenderness ratio, the valid size is given in Table 7 .

Table 4. Retention time constraint governed $d$ and $L$ selection for a 2-phase separator.

\begin{tabular}{|c|c|c|c|}
\hline \multicolumn{4}{|c|}{ Liquid Retention Time Constraint } \\
\hline$D$ & $L_{\text {eff }}$ & $L_{s}$ & $12 L_{s s} / d$ \\
\hline 30 & 23.8 & 26.3 & 10.520 \\
\hline 36 & 16.54 & 19.4 & 6.520 \\
\hline 42 & 12.15 & 15.65 & 4.470 \\
\hline 48 & 9.30 & 13.3 & 3.325 \\
\hline 54 & 7.35 & 11.85 & 2.630 \\
\hline 60 & 5.95 & 10.95 & 2.190 \\
\hline 66 & 4.92 & 10.42 & 1.895 \\
\hline
\end{tabular}

Table 5. Selected 2-phase process vessel size.

\begin{tabular}{cccc}
\hline$D$ & $L_{\text {eff }}$ & $L_{s}$ & $12 L_{s s} / d$ \\
\hline 48 & 9.30 & 13.3 & 3.325 \\
\hline
\end{tabular}


Table 6. Liquid capacity constraint $d$ and $L_{\text {eff }}$ combinations.

\begin{tabular}{cccc}
\hline $\boldsymbol{d}(\mathrm{in})$ & $\boldsymbol{L}_{\text {eff }}(\mathrm{ft})$ & $\boldsymbol{L}_{\text {ss }}(\mathrm{ft})$ & $\mathbf{1 2} L_{\text {ss }} / D$ \\
\hline 36 & 83.82 & 85.15 & 28.38 \\
42 & 61.58 & 62.91 & 17.97 \\
48 & 47.58 & 48.48 & 12.12 \\
54 & 37.25 & 38.58 & 8.57 \\
60 & 30.18 & 31.51 & 6.30 \\
66 & 24.94 & 26.27 & 4.78 \\
72 & 20.95 & 22.28 & 3.71 \\
84 & 15.39 & 16.72 & 2.39 \\
90 & 13.41 & 14.74 & 1.97 \\
\hline
\end{tabular}

Table 7. Sized three phase process vessel.

\begin{tabular}{cccc}
\hline$D$ & $L_{\text {eff }}$ & $L_{s s}$ & $12 L_{s s} / D$ \\
\hline 72 & 20.95 & 22.28 & 3.71 \\
\hline
\end{tabular}

\subsection{Simulation Results}

The process flow diagram obtained from the Hysys simulation of the two stage separation is shown in Figure 1.

The two stage treatment process is comprised of a first two phase separator followed by a second stage three phase separation. The efficiency of the process is in the propensity to determine optimal operating pressures of the vessels. Thermodynamic properties of the fluid system have to be carefully altered to permit the desired phase separation. Table 8 and Figure 2 represent the material balance across the two phase separation stage and two phase molar flow recovery across the two phase separator respectively.

The Gas rate dropped from 132,918 Ibmole/hr to 128,652 Ibmole/hr (difference of $4266 \mathrm{Ibmole} / \mathrm{hr}$ ) because of high operating pressure in the vessel causing gas entrainment in the liquid stream. The liquid stream also increased from 8704 Ibmole/hr to $12,971 \mathrm{Ibmole} / \mathrm{hr}$ consequent upon the high operating vessel pressure validating the effectiveness of the operating pressure selected.

Table 9 and Figure 3 represent the obtained material balance across the three phase separator and the molar flow recovery across the three phase separator respectively.

Here we observed all the compensations required to balance out materials. Entrained gas in liquid from two-phase separation was accounted for at 4375 Ibmole/hr. The flow rate of oil slightly increased by $270 \mathrm{Ibmole} / \mathrm{hr}$ as a result of low pressure of the separator causing lighter end hydrocarbon to condense into liquid oil while the water flow rate dropped by $359 \mathrm{Ibmole} / \mathrm{hr}$. This also was due to flashing of the hydrocarbon content of the water feed stream.

\section{Conclusions}

The modeled equipment when sized with Mathlab gave standard sizes available in the industry today. The sized equipment was used to run the dynamic simulation of the two-stage separation process. The multiphase fluid from the well 


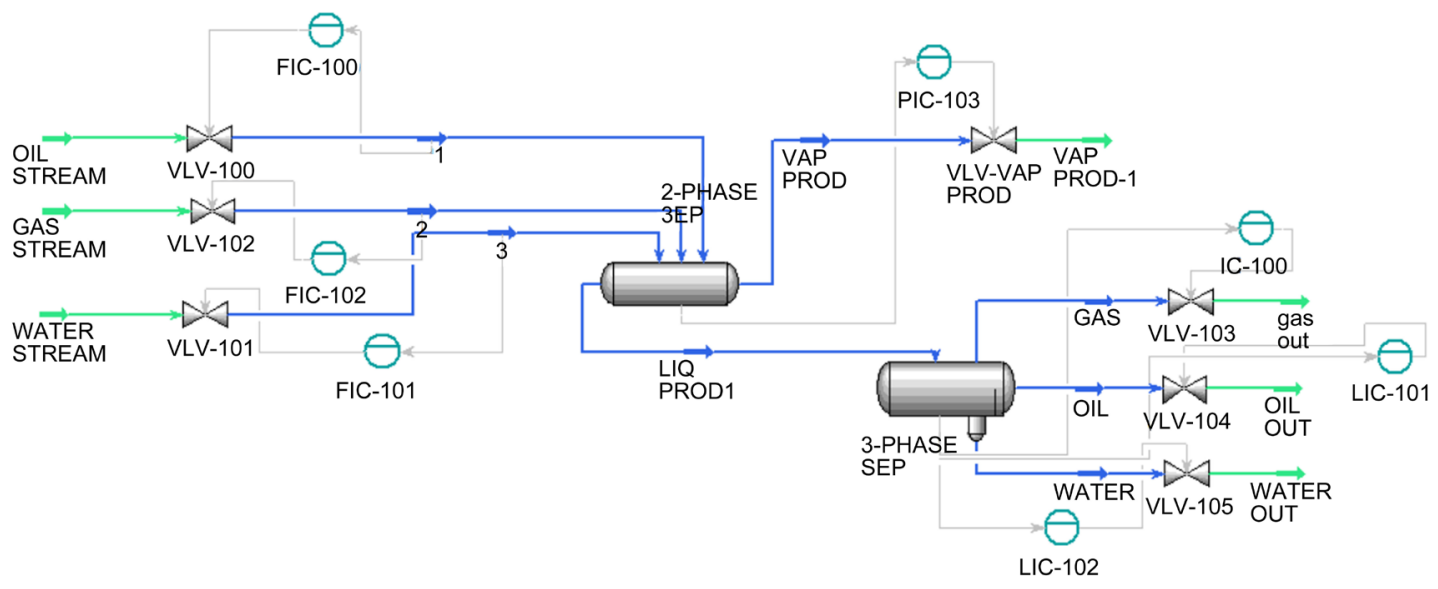

Figure 1. Aspen Hysys dynamic simulation of the two stage separation.

\section{2-Phase Recovery}

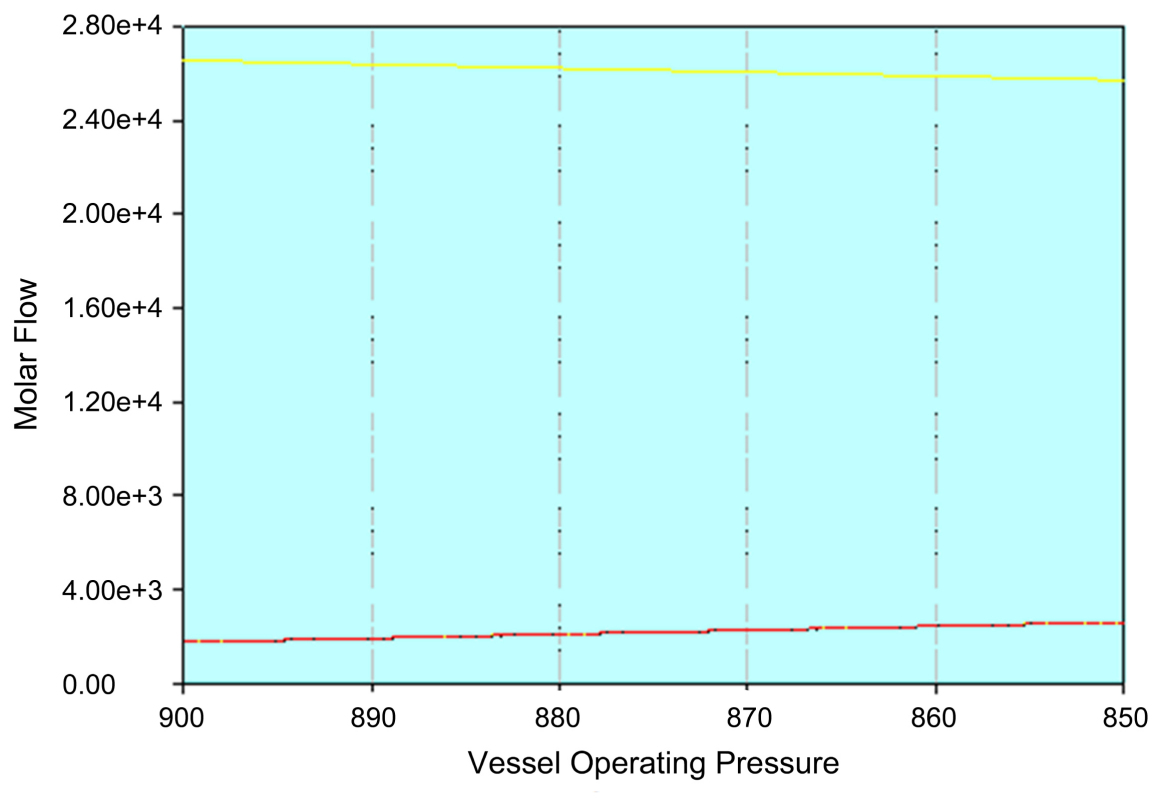

Pressure Vs Gas Flow Recovery

Pressure Vs Liquid Recovery

Figure 2. Phase recovery from 2-phase separator with operating pressure.

Table 8. Two phase material balance.

\begin{tabular}{ccccc}
\hline & Unit & Mixture & Vapour Product & Liquid Product \\
\hline Vapour Fraction & & 0.907377905 & 1 & 0 \\
Temperature & $\mathrm{F}$ & 120.1248562 & 118.2104249 & 118.2104249 \\
Pressure & Psia & 900 & 850 & 850 \\
Molar Flow & lbmole/hr & $141,624.0345$ & $128,652.9011$ & $12,971.13346$ \\
Mass Flow & lb/hr & $3,412,922.091$ & $2,544,818.929$ & $868,103.1621$ \\
Liquid Volume Flow & USGPM & $17,780.03815$ & $14,978.78354$ & 2801.254605 \\
\hline
\end{tabular}


Table 9. Three phase separator material balance.

\begin{tabular}{cccccc}
\hline & Unit & Liquid Product-1 & Gas & Oil & Water \\
\hline Vapour Fraction & & 0 & 1 & 0 & 0 \\
Temperature & $\mathrm{F}$ & 118.210425 & 87.4358 & 87.4358 & 87.4358 \\
Pressure & psia & 850 & 50 & 50 & 50 \\
Molar Flow & lbmole/hr & $12,971.1335$ & 4375.621 & 7892.15 & 703.3626 \\
Mass Flow & $\mathrm{lb} / \mathrm{hr}$ & $868,103.162$ & $122,325.7$ & 733,106 & $12,671.52$ \\
Liquid Volume Flow & USGPM & 2801.25461 & 595.6206 & 2180.276 & 25.35793 \\
\hline
\end{tabular}

\section{3-Phase Recovery}

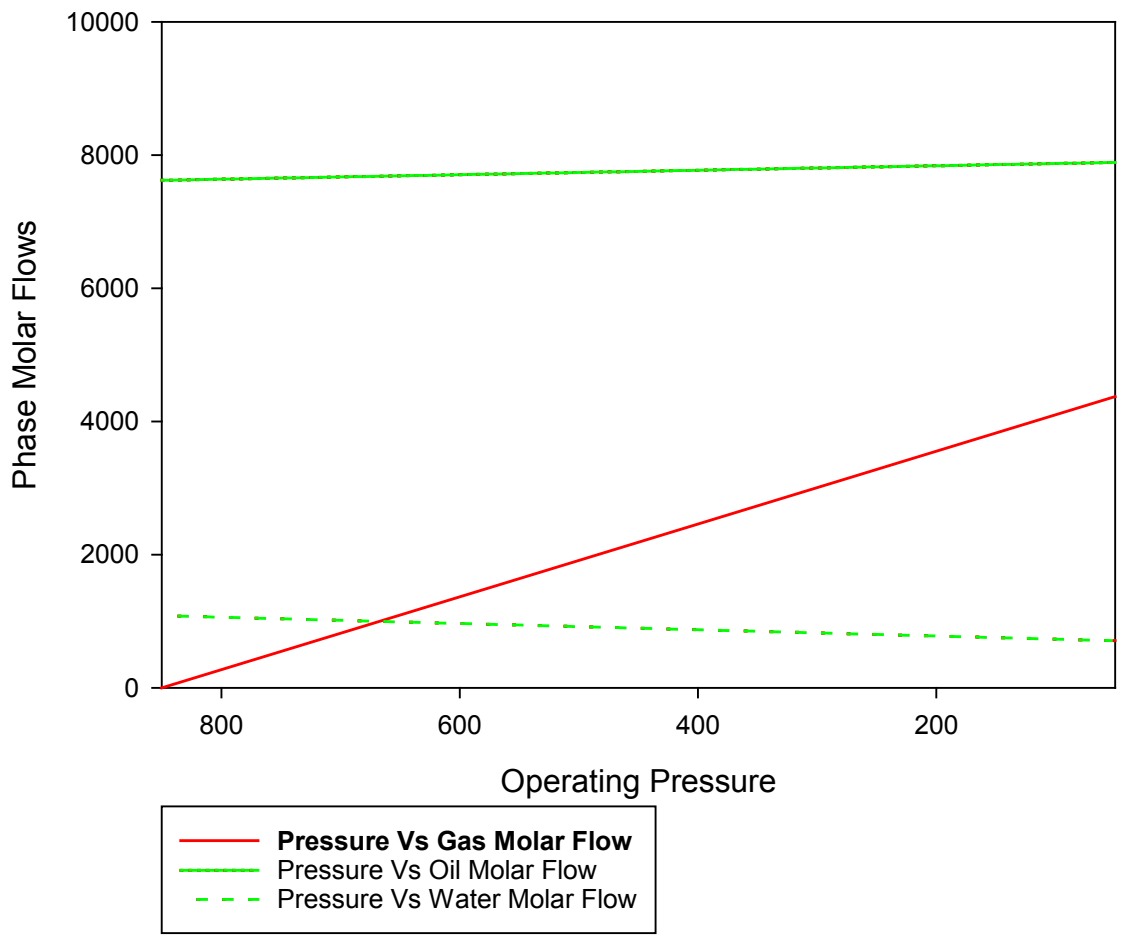

Figure 3. 3-Phase recovery with operating pressure.

entered the two phase separator where about $96.77 \%$ of the gas flashed with the rest entrained with the liquid. The liquid from the first separator enters the second three-phase separator where the remaining 3.23\% of the initial gas is flashed plus additional $0.083 \%$ light end hydrocarbons flashed. The oil and water were fully separated with additional $3.42 \%$ hydrocarbon recovery from other phases. The produced water from the process was treated to disposal standard in the produced water treatment unit whilst the gas was clear of droplets through the knock-out drum to the flare. The simulation and sized equipment results proved the ideality of the models.

For future works should include models for chemical injection and heating system(s) in case of hydrate and wax formation. 


\section{Conflicts of Interest}

The authors declare no conflicts of interest regarding the publication of this paper.

\section{References}

[1] Atalla, F.S. and James, H.T. (2007) Modeling and Control of Three-Phase Gravity Separator in Oil Production Facilities. 42, 291-293.

https://www.academia.edu/9689973/Modeling_and_Control_of_Three-Phase_Gravi ty_Separators_in_Oil_Production_Facilities

[2] Amanat, C.U. (1999) Oil Well Testing Handbook. Petroleum Extension Service a Dictionary for the Petroleum Industry Third Edition.

[3] Arnold, K. and Stewart, M. (1999) Surface Production Operation: Design of Oil-Handling Systems and Facilities. 2nd Edition, Vol. 1, Butterworth-Heinemann, Woburn, MA.

[4] Williams Lyons, C. and Gary Plisga, J. Standard Handbook of Petroleum \& Natural Gas Engineering. Vol. 2.

[5] Powers, M.L. (1990) Analysis of Gravity Separation in Freewater Knockouts. SPE Production Engineering, 5, 52-58. https://doi.org/10.2118/18205-PA

[6] API RP 45, 1998.

[7] Saeid, M. and Williams, P.A. (2012) Handbook of Natural Gas Processing and Transmission. Vol. 2.

[8] Schlumberger Well Test Manual.

[9] API 12J, 1989. 